\title{
Opting Out of Congress: Partisan Polarization and the Decline of Moderate Candidates. By Danielle M. Thomsen. Cambridge: Cambridge University Press, 2017. 202p. \$99.99 cloth
}

\author{
Soren Jordan
}

2018

This is the final version as it appears for the citation:

Jordan, Soren. 2018. "Opting Out of Congress: Partisan Polarization and the Decline of Moderate Candidates. By Danielle M. Thomsen. Cambridge: Cambridge University Press, 2017. 202p. \$99.99 cloth.” Perspectives on Politics 16 (1): 230-232.

DOI: $10.1017 /$ S1537592717003140

The page numbers here are consistent with the published version. Corresponding author: (sorenjordanpols@gmail.com). 
Opting Out of Congress: Partisan Polarization and the Decline of Moderate Candidates. By Danielle M. Thomsen. Cambridge: Cambridge University Press, 2017. 202p. \$99.99 cloth.

—Soren Jordan, Auburn University

We have learned a great detail about polarization in the last decade. Scholars have provided sophisticated evidence 
on the causes, especially, of elite polarization. Two mechanisms are at play: replacement (when moderates are replaced electorally by more extremists) and conversion (when the same members grow more ideological. But these mechanisms alone do not explain why certain members are replaced instead of others: especially those who do not run for reelection.

Danielle M. Thomsen provides a refined answer. In Opting Out of Congress, she illustrates how the benefit of being a member of Congress depends on party fit: whether the party stands for policies that the legislator or potential legislator prefers (p. 31). A (potential) member's party fit affects his or her ability to achieve policy goals, advance an agenda in Congress, and enjoy daily life in the institution. Members who fit the ideology of the party accomplish more of these three goals. Accordingly, as the parties grow more polarized, moderates fare worse with party fit, see less benefit from a seat in Congress, and abstain from running altogether, creating a problem in the supply of moderate candidates.

The evidence here is voluminous. Thomsen uses a variety of ideological scores, including those not based on roll-call voting (which allow the comparison of non-members), to measure how well a member fits the ideology of party leadership. Thomsen also gives serious attention to the pool of potential moderate candidates, especially those in state legislatures, the strongest traditional pool of candidates for higher office. We learn that moderates who do not fit with party leadership are statistically less likely to run for higher office, especially the U.S. House, than ideologues (p. 90). This is especially true of open seats, where ideologues are more likely to run. Perhaps most importantly, Thomsen illustrates a potential driver of asymmetric polarization, where Republican ideologues are much more likely than Democratic ideologues to run for open seats (p. 111). Conversely, once in Congress, moderate members are more likely to retire, even if their electoral margins are still relatively safe (p. 130).

Thomsen employs a variety of data, but a real strength of her work is the subtle context afforded by elite interviews. Thomsen uses anonymous interviews with former (moderate) members of Congress to demonstrate that the day-to-day life of a Congressperson who does not fit the party is at best personally unpleasant and at worst politically unrewarding. Most of the 22 elites she interviews share a common course to their Congressional careers: being a moderate in politics was tolerable, even rewarding, in the 1990s, but they "got tired of it" (p. 135) as polarization pushed them out-of-step with their party. The context of these direct interviews also helps us remember the person in politics. Too often, it easy to lapse into thinking of Congresspeople as single-minded seekers of reelection who are not also human beings with feelings and personalities. But seeing the words of former moderate members reminds us that a polarized, confrontational Congress might be an unpleasant workplace on a personal level.

This connection is especially interesting given other recent work in the field. In More Than a Feeling (2017), Adam J. Ramey, Jonathan D. Klingler, and Gary E. Hollibaugh illustrate how polarization is related to the Big 5 personality scale. Thomsen's own analysis and interviews supplement this idea, especially when she notes that "moderates tend to be pleasant, genteel people" (p. 134). Already flustered by the lack of fit within their own party, such moderates might look at the abrasive culture created by a partisan environment and shun a career beyond state or local office altogether. As the political environment becomes more conflictual, on personal as well as policy lines, only those with a taste for combat in their personality might be driven to seek and retain office.

This insight is especially important when we consider polarization moving forward. Thomsen suggests that moderates "kept the parties anchored at the center" (p. 50), but if certain personalities are more driven to seek party leadership positions (which dole out the benefits that underscore the importance of party fit), and those same personalities are more likely to adopt relatively extreme ideologies, it will not be enough to simply elect moderate members and expect a decline in polarization. Thomsen makes the point clear: party fit is important because of the potential influence of the member in the policymaking process. As long as leadership is dominated by outspoken personalities with a penchant for ideological conflict, day-to-day benefits are unlikely to be distributed to moderate members, causing moderates not to run.

The influence of personality might also help answer the question of "party fit" that Thomsen doesn't ask: Extreme ideologues face the same problem of not fitting their party ideology. What causes these individuals to increasingly be drawn to a career in Congress? Personality also provides an alternate explanation to the party-specific and gender-specific stories Thomsen uncovers, as both party identification and gender are associated systematically with personality.

Some unanswered questions remain. Party fit is the main yardstick by which candidates measure the utility of a career in Congress, but polarization causes the scale of the measure for party fit is asymmetric by party and varies over time (p. 107). If a party polarizes, the possible range of values of party fit is naturally going to grow, as the party grows more extreme. Yet this will only occur in the "negative" direction: a polarizing party can never cause moderates to fit that party better. Unfortunately for us, this means that if one party polarizes asymmetrically, our models might reveal that one party plays an exacerbated role in polarization overall, simply because the independent variable in that party has more variation temporally. Interpretation is also difficult: Thomsen interprets the 
empirical results from a pooled model, in which several years' worth of potential "party fits" are mixed, as a cohesive unit, as if "party fit" means the same thing in 2000 as it does in 2010 (for instance, at p. 91), which we know not to be true. Future work might consider the more explicit introduction of time dynamics in these models.

Another challenge is less addressed: very few people run for Congress. Not just of a moderate stripe, but of any stripe. More commonly, we might call this a problem of rare events: and we have grown to understand that explaining rare events is much more difficult than explaining events that occur with some frequency. Explaining non-occurrences becomes easier than explaining occurrences: potentially problematic if our theory explains why events do not happen (moderates do not run). Here, positive events-where we successfully explain candidacy-are almost entirely determined by open seats. This predictor, though, is never interacted with the theoretical predictors of party fit and distance. Future work might consider an explicitly rare events approach, interacting predictors with an open seat, or just looking at open seat races alone.

This work offers an interesting and thorough look at the "supply" of candidates that we often ignore when studying Congress. It moves our understanding of polarization forward by focusing our attention on those individuals actually (not) running for office and the systematic differences between them that lead to polarization. 